\title{
UM NOVO MÉTODO PARA OBTER A FUNÇÃO DE TRANSMISSÃO EM DIFRATOMETRIA DE RAIOS-X POR MONOCRISTAIS
}

\author{
EDUARDO ERNESTO CASTELLANO
}

Tese apresentada ao Instituto de Física e Química de São Carlos, Universidade de São Paulo, para obtenção do Titulo de Livre Docente.

IFQSC - USP

Departamento de Física e Ceŝricias dos Materiais

São Carlos - 1978 
UM NOVO METODO PARA OBTER A FUNÇAO

DE TRANSMISSAO EM DIFRATOMETRIA DE

RAIOS-X POR MONOCRISTAIS

Eduardo Ernesto Castellano

Tese apresentada ao Instituto de Física e Química de São Car los, Universidade de São Pau1o, para obtenção do Título de Livre Docente

IFQSC - USP

Departamento de Física e Ciências dos Materiais São Carlos- 1978 


\section{IND ICE}

Agradecimentos

Resumo

Abstract

Introdução

CAPITULO I

I.1 Generalidades.......................

I.2 Método de North, Phyllips e Mathews.........?

I.3 Método de Kopfmann e Huber...............4

I.4 Método de Katayama, Sakabe e Sakabe.......... 5

I.5 Definição do problema.................

CAP ITULO II

II.1 Formulação do mëtodo proposto.............

II.2 Descrição do arranjo experimental.......... 12

II.3 Cálculo das direções dos feixes primário e se cundário com respeito a um sistema de coordenadas fixo ao cristal na geometria Kappa........ 16

CAP ITULO I I I

III.1 Solução do sistema de equações............. 21

III.2 Sistema de programas desenvolvido........... $2 \downarrow$

CAPITULO IV - Ap1icação a um caso teste............... 2t

CAPITULO V - Discussão e sugestão para um melhoramento eventual na precisão do mêtodo.............

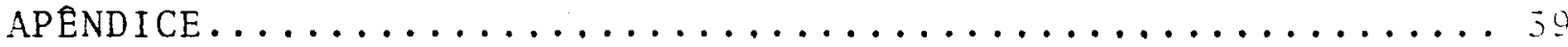

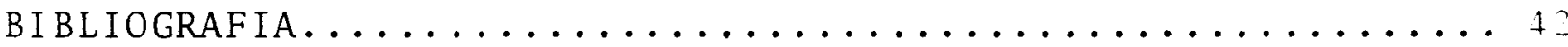




\section{AGRADECIMENTOS}

Agradeço a todos os professores, funcionários e estudantes do Departamento de Física e Ciências dos Materiais que colaboraram direta ou indiretamente na realização desta tese.

Em particular agradeço:

Aos Professores Yvonne e Sergio Mascarenhas peloapoio, estímulo e confiança que me ofereceram desde o início das minhas atividades no Departamento.

Ao Chefe do Departamento de Física e Ciências dos Ma teriais, Prof.Milton Ferreira de Souza, pelo estimulo e facilidade proporcionados na execução desse trabalho.

Ao Prof.Jan Slaets pela assistência com o equipamento experimental e por muitas valiosas discussões.

Ao Sr.Durval A.de Ulhôa Cintra pelo auxílio com o português do manuscrito.

A Profa.Regina Helena de A.Santos pelas observações crí ticas, nem sempre seguidas, sobre o português e estilo da apre sentação do trabalho.

Ao técnico, Carlos A.de Simone, pelos desenhos.

A Loreni Bastos Pereira Ruas pela datilografia.

Ao Paulo Roberto Beatrice pela impressão da tese. 
Propōe-se um novo método para a correção do efeito de absorção que se apresenta na difratometria de raios-x por monocristais.

Visa-se particularmente a análise cristalográfica de proteínas, embora o método possa ser convenientemente utilizado também em pequenas estruturas.

Primeiramente apresenta-se uma anālise crítica dos pro cedimentos atualmente disponiveis na literatura; estes constitu em a base para uma formulação alternativa que é desenvolvida em continuação.

O método utiliza a informação contida nas medidas da intensidade de uma mesma reflexāo, efetuada para distintos valo res do àngulo azimutal, e a informação contida nas reflexões simetricamente equivalentes. A função de transmissão é desenvolvi da em sërie de Fourier e mediante uma aproximação conveniente mente introduzida é gerado um sistema de equações lineares nos coeficientes de expansão, cuja solução é obtida pelo critērio de minimos quadrados.

0 procedimento pode ser usado em qualquer tipo de difratômetro de quatro círculos; em particular foi implantado para utilização com o difratómetro de geometria Kappa CAD-4, do Departamento de Física e Ciências dos Materiais de São Carlos. Para esse fim foi desenvolvido um sistema automatizado de pro gramas FORTRAN.

Apresentam-se os resultados obtidos com um cristal de teste, os quais permitem uma avaliação crítica do método. 
A new method for absorption correction of single crystal $x$-ray difractometric data is proposed.

It is particularly aimed at crystallographic analysis of proteins although it can profitably be applied to small structures as well.

First a critical review of the methods currently available in the literature is presented and then an alternative procedure is developed.

The method makes use of the information contained in the intensities of a same reflection measured at different azimuthal angles and also the information contained in symmetry related reflections. The transmission function is developed in Fourier series and by introducing a convenient approximation, a linear system of equations is obtained, which is solved for the coeficients of the expansion by the least squares procedure.

The method can in principle be used in conjunction with any four circle difractometer. In particular it has been implemented for the Kappa geometry CAD-4 difractometer present1y in use in São Carlos at the Department of Physics and Materials Science, for which an automatized FORTRAN program has been written.

Results obtained on a test crystal, which permit a critical evaluation of the method, are reported. 
A determinação de estruturas cristalinas por difração de raios-X é frequentemente realizada desprezando-se o efeito de absorção dos feixes primârio e difratado dentro do cristal. E, entretanto, conhecida a importância de um tratamento adequado dos efeitos da absorção quando se requerem resultados de alta precisão, particularmente de parâmetros térmicos, ou quando se deseja localizar com precisão átomos leves em presença de outros de número atômico muito mais elevado, ou quando se utilizam diferenças de intensidades na determinação de fases como acontece na análise da estrutura de proteinas pelo método da substituição isomórfica. Por esses motivos, a determinação de correções por absor ção tem sido extensamente estudada e um grande número de métodos têm sido propostos para seu tratamento.

Os métodos em uso até 1958 se encontram resumidos em "International Tables for X-Ray Crystallography (1)". Os métodos mais modernos, atualmente utilizados em estudos difratométricos de estruturas de proteínas são descritos no presente trabalho.

No decorrer de um estudo realizado no Laboratório de Raios-X do Departamento de Física e Ciências dos Materiais de São Carlos sobre um complexo de mioglobina com ions cobre ${ }^{(2)}$, percebeu-se que grande parte do ruido surgido sistematicamente nos ma pas (diferença) de densidade eletrônica calculados provinha da falta de correção por efeito da absorção. O estudo subsequente dos métodos atualmente utilizados nesses tipos de trabalho sugeriu a possibilidade de desenvolver uma variante com duas caracte rísticas de utilidade prática: simplicidade de implementação e ge neralidade de aplicação.

0 método requer o uso de um difratômetro de quatro cír culos e um computador digital, e adapta-se perfeitamente ao "hardware" do Laboratório de Cristalografia do Departamento de Física 
e Ciências dos Materiais de São Carlos.

o presente trabalho se desenvolve de acordo com a seguinte sequência:
Capitulo I - Descrevem-se os métodos atualmente em uso, assinalando-se suas vantagens e desvantagens ;

Capítulo II - Propõe-se um método alternativo;

Capítulo III- Descrevem-se o sistema de cảlculo e os programas de computação desenvolvidos:

Capítulo IV - Analisa-se a aplicação do método a um caso teste;

Capitulo V - Discute-se a precisão do método e a possibilidade de melhorā-la. 
ANÁLISE DOS METODOS EM USO E DEFINIÇAOO DO PROBLEMA

\section{1 Generalidades}

Os métodos particularmente aplicáveis à correção por absorção em experiências difratométricas são essencialmente de dois tipos: analíticos e semi-empíricos. Os primeiros são base ados na integração da função de absorção

$$
\frac{1}{V} \int_{V O L} \exp (-\mu(p+q) d V
$$

onde $p$ e $q$ são os caminhos percorridos pelos feixes incidente e difratado para cada elemento de volume dV e $\mu$ é o coeficiente de absorção 1 inear $(3,4)$.

No estudo de estruturas complexas esses métodos apresentam duas desvantagens fundamentais. A primeira é que o tempo de computação requerido quando vários milhares de reflexões têm que ser corrigidas (como no caso do estudo de proteinas) tornase, em geral, desmedidamente grande. A segunda, e mais importan te, consiste no fato de que esses mëtodos requerem medidas precisas das dimensões cristalinas, o que é muitas vezes impossível, devido à morfologia desfavorável da amostra.

o estudo de proteinas oferece uma dificuldade adicional; devido a ter-se que levar em conta a absorção ocorrida na montagem do cristal, que usualmente consiste num capilar de vidro em que o cristal fica encerrado em contacto com uma porção de 1 íquido mãe.

Por essas razões, no trabalho estrutural de proteínas utilizam-se exclusivamente os métodos semi-empíricos. Estes se 
baseiam na utilização da informação obtida ao medir-se uma mesma reflexão em diferentes posições do cristal, conseguidas por rotação ao redor do vetor de difração, ou na informação contida nas reflexões equivalentes de um cristal com alta simetria de Laue.

São três os métodos semi-empíricos atualmente utilizạ dos em correções por absorção na anảlise de proteínas (eventual mente, esses métodos são utilizados tambẻm em pequenas estruturas ):

\section{I.2 Método de North, Phyllips e Mathews}

Este é o método menos sofisticado, embora seja o mais utilizado dos três, e se baseia numa modificação do método de Furnas ${ }^{(6)}$.

Uma curva de absorção relativa é experimentalmente obtida a partir da variação de intensidade de uma reflexão quando - cristal é submetido a rotação ao redor da normal à correspondente familia de planos (direção azimutal).

Suponhamos, para simplificar a idéia, que o cristal tem eixos ortogonais e estả montado ao longo do eixo c. Então. na montagem típica de equinclinação (standard setting ${ }^{(7)}$ ), a re flexão $00 \ell$ fica na posição de reflexão para todo o valor do ângulo azimutal $\psi$. Nessa montagem os feixes incidente e difrata do ficam igualmente inclinados em relação ao eixo de rotação, de maneira que a média dessas duas direções fica no plano per pendicular ao eixo de rotação (Figura 1 ).

A diferença de intensidade da reflexão 00e ê medida a intervalos de $10^{\circ}$ a $15^{\circ}$ do ângulo azimutal, obtendo-se assim $\underline{u}$ ma curva de transmissão relativa em função de $\psi$.

o coeficiente de transmissão para qualquer outra re flexão hke é obtido mediante a aproximação 


$$
T(h k l)=\left\{T\left(\psi_{i}\right)+T\left(\psi_{d}\right)\right\} / 2
$$

onde $\psi_{i}$ e $\psi_{d}$ são os ângulos azimutais dos feixes incidente e di fratado, respectivamente.

Este método se baseia nas seguintes hipóteses:

1) a absorção é função unicamente de $\psi$, o que depen de, entre vários outros fatores, da forma do cristal e do inter valo do ângulo de Bragg $\theta$ explorado; esta hipótese é, em geral, fortemente restritiva.

2) a transmissão para uma reflexão arbiträria pode es crever-se como sendo a média dada pela equação (I.2). Apesar des sas sérias desvantagens, o método tem o atrativo de requerer o mínimo de determinações experimentais e de cálculos.

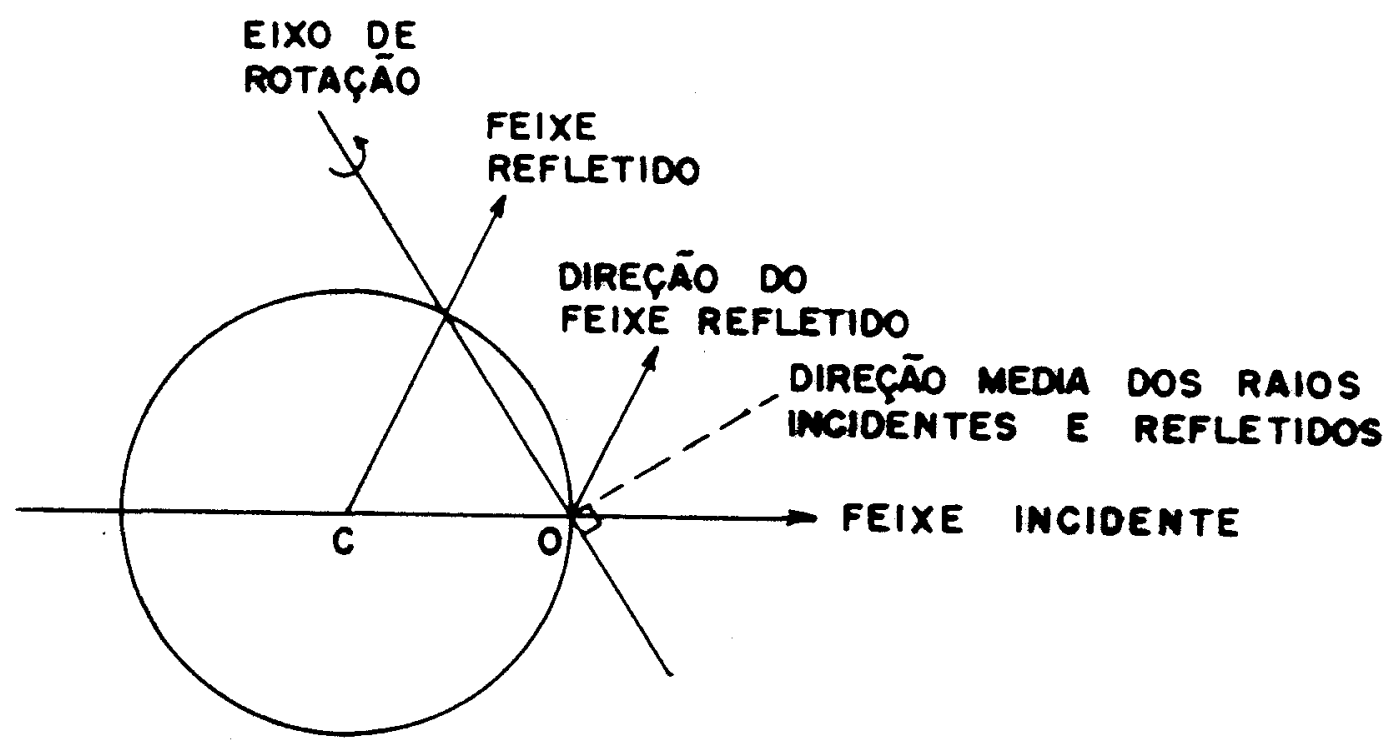

Figura 1 
I.3 Método de Kopfmann e Huber

Este método é muito mais sofisticado e inerentemente mais preciso que o anterior. Sua finalidade é obter uma superfí cie de absorção para o cristal a partir das intensidades de várias reflexões, medidas para diferentes ângulos azimutais. Isso é feito da seguinte maneira: de cada medida obtém-se uma equa ção da forma

$$
\mathrm{I}_{\underset{\sim}{\mathrm{p}}, \underset{\sim}{\mathrm{s}}}^{\mathrm{s}}=\mathrm{I}^{\mathrm{H}} \mathrm{A}_{\underset{\sim}{p}, \underset{\sim}{s}}
$$

onde $\mathrm{I}_{\mathrm{p}, \mathrm{s}}^{\mathrm{H}}$ é a intensidade da reflexão $\mathrm{H}$ para o ângulo azimutal em que os feixes primário e secundário estão na direção de $\underset{\sim}{p}$ e s, respectivamente; $\mathrm{I}^{\mathrm{H}}$ é a intensidade (desconhecida) que cor responderia à transmissão unitāria e $A_{\underline{p}} \underset{\sim}{s} \underset{\sim}{e}$ a transmissão para as direções $\underset{\sim}{p}$ e $\underset{\sim}{s}$.

Introduzindo a aproximação (Vide Capitulo V)

$$
A_{\sim}^{p} \underset{\sim}{s}=A_{\sim}^{\prime} \cdot A_{\sim}^{\prime}
$$

a equação (I.3) transforma-se em

$$
I_{\sim}^{H}, \underset{\sim}{\mathrm{H}}=I^{\mathrm{H}} \stackrel{\sim}{\mathrm{p}}^{\prime} \cdot \mathrm{A}_{\underset{\sim}{s}}^{\prime}
$$

Tomando o logaritmo, obtêm-se um sistema de equaçōes lineares no logaritmo das incógnitas A'. A' é calculada nos pon tos de uma rede de valores de $\underline{p}$, previamente definida. Como os valóres de $\underset{\sim}{p}$ e $\underset{\sim}{s}$ na equação (I.35) não coincidem em geral com os pontos da rede, efetua-se uma interpolação 1 inear, pesando os va lores de A' vizinhos ao ponto considerado de acordo com sua dis tância angular ao mesmo. O conjunto (super determinado) de equa ções lineares é reduzido às equações normais e resolvido para 
os valores de $A^{\prime}$ nos pontos da rede e para os $I^{H}$.

Este mētodo se baseia em aproximações mais exatas que o anterior e utiliza muito mais informações experimentais. Re quer necessariamente o uso de um difratómetro de quatro circu los para poder girar o cristal ao redor de direções arbitrārias. Apresenta dois inconvenientes, do ponto de vista de cálculo: por um lado, a definição dos pontos da rede é em geral diferente pa ra diferentes cristais e a sua escolha não é óbvia; por outro lado, acontece frequentemente que os valores de $A^{\prime}$ em algunspon tos da rede ficam pobremente definidos. Huber e Kopfmann (9) sugerem, nesse caso, efetuar um "smoothing" da função por meio de uma equação de regressão mủitipla da forma

$$
\mathrm{A}_{\sim} \underset{\sim}{\mathrm{s}}=\mathrm{b}_{\mathrm{o}}+\mathrm{b}_{1} \mathrm{f}_{1}+\mathrm{b}_{2} \mathrm{f}_{2}+\ldots=\mathrm{I}_{\sim}^{\mathrm{I}} \underset{\sim}{\mathrm{s}} / \mathrm{I}^{\mathrm{H}}
$$

onde $f_{1}, f_{2},,, f_{n}$ são funções não-lineares de seis variáveis, a saber, os cosenos diretores das direções dos feixes incidente e difratado.

I.4 Método de Katayama, Sakabe e Sakabe ${ }^{(10)}$

Baseia-se na comparação entre as intensidades de vä rios grupos de reflexões equivalentes, isto ë, reflexões rela cionadas pela simetria de Laue do cristal. Supõe-se que as dife renças observadas são efeito exclusivo da absorção. As diferenças devidas à (eventual) dispersão anômala são tratadas como e ros randómicos. A idēia consiste em encontrar a função de absor ção'A $\left.\underset{\sim}{\left(h_{i}\right.}\right)$, que minimiza o erro quadrático

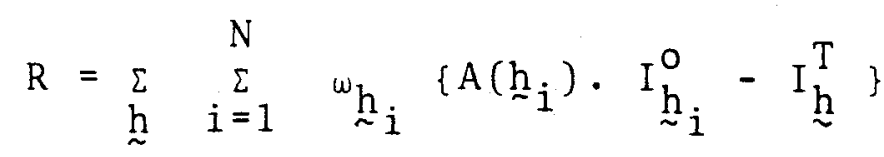

onde cada i representa uma reflexão equivalente para um dado $\underset{\sim}{h}$; 
$I^{\circ}$ e $I^{T}$ são as intensidades observada e verdadeira, respectivamente; wè um fator de peso e $\mathrm{N}$ é o número total de reflexões $\underline{\mathrm{e}}$ quivalentes para cada $\underset{\sim}{\mathrm{h}}$.

Como $I^{\mathrm{T}}$ não é conhecida, substitui-se pelo valor mé dio

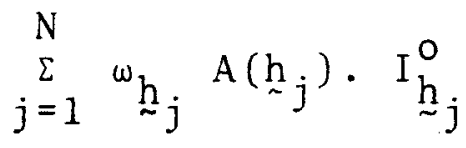

Como a função $A\left(\underset{\sim}{h_{i}}\right)$ deve ser periódica, utiliza-se o seguinte de senvolvimento

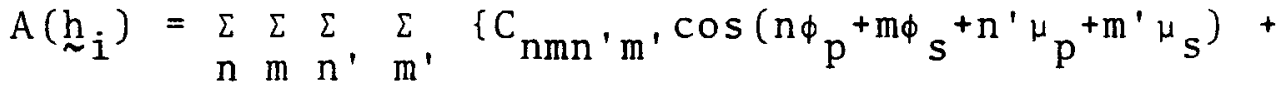

$$
\begin{aligned}
& +S_{n m n^{\prime} m^{\prime}} \sin \left(n \phi_{p}+m \phi_{s}+n^{\prime} \mu_{p}+m^{\prime} \mu_{s}\right)
\end{aligned}
$$

onde os coeficientes $C$ e $S$ devem ser determinados e $\phi_{p}$, $\phi_{s}$, ${ }_{p}$, $u_{s}$ sāo ângulos que definem as direções dos feixes primário e di fratado, respectivamente.

A absorção varia suavemente em relação às direções dos feixes, razão pela qual a série (I.9) deve convergir rapidamente.

A determinação dos coeficientes $C$ e $S$ se efetua na for ma usual pelo critério dos mínimos quadrados. O problema que se apresenta é que se a série (I.9) è desenvolvida até uma ordem su ficiente para a reprodução aceitável da função experimental, o numero de coeficientes cresce muito acima do valor prático. Por exemplo, se todos os indices tomam valores entre 0 e 4 , o número de coeficientes è de 1.249 .

Katayama et al mostraram que se o cristal é montado na posição de equi-inclinação (equivalente à posição standard no di fratômetro de quatro circulos $^{7}$ ), a série (I.9) pode ser aproxima da por um desenvolvimento bidimensional 


$$
A(\underset{\sim i}{h})=\underset{n}{h_{m}} \sum\left\{C_{n m} \cos (n \psi+m \mu)+S_{n m} \sin (n \psi+m \mu) \cos n \Delta \psi\right\}
$$

onde $\psi$ é o ângulo difratométrico associado com o eixo da cabeça goniométrica, e $\mu$ é o ângulo de equi-inclinação.

A restrição mais importante deste método é que a exigência da montagem de equi-inclinação, essencial para reduzir a magnitude do problema de forma que seja tratável praticamente, impede a generalização da idéia para utilizar medidas efetuadas para diferentes ângulos azimutais.

\section{5 Definição do problema}

O método que se propõe no presente trabalho compatibi liza algumas das idéias dos métodos resumidos, visando à apre sentação das seguintes características:

I - Dados obtidos em difratômetros de quatro círculos com o cristal em montagem arbiträria.

I - Uso de curvas azimutais ou reflexões equivalentes ou ambos os tipos de dados simultaneamente.

III - Algoritmos independentes do cristal estudado.

IV - "Smoothing" da correção automaticamente incluido.

V - Simplicidade de implantação.

$V I$ - Economia de tempo de computação. 


\section{CAPITULO I I}

METODO

\section{I . 1 Formulação do método proposto}

Suponhamos que $\underset{\sim}{h}$ denota qualquer dos vetores equiva lentes de uma reflexão dada e j o conjunto dos quatro ângulos que definem as posições de reflexão da familia de planos $\underset{\sim}{\mathfrak{h}}$ num difratômetro de quatro círculos. Chamemos de $\mathrm{I}^{\mathrm{O}}(\mathrm{h}, \mathrm{j})$ a intensidade observada de uma reflexão do vetor recíproco $\underset{\sim}{\mathrm{h}}$ na montagem j.

Para um mesmo $\underset{\sim}{h}$ duas reflexões terão diferentes montą gens j se: a ) seus ângulos azimutais são diferentes; b) se se trata de diferentes posiçōes de simetria de Laue, ou c) diferem simultaneamente em ambas as coisas.

Se a absorção pode ser considerada desprezível, todas as reflexões do conjunto $I^{\circ}(\underset{\sim}{h}, j), j=1 \ldots$ devem ser idênticas. Quando a absorção não for desprezivel, a intensidade $I^{\circ}(\underset{\sim}{h}, j)$ es tará relacionada à intensidade verdadeira $\mathrm{I}^{\mathrm{T}}(\underset{\sim}{\mathrm{h}})$, definida a menos de uma constante multiplicativa comum a todas as reflexões como a intensidade correspondente à absorção nula, mediante

$$
\left.I^{O} \underset{\sim}{(h, j}\right)=I^{T} \underset{\sim}{(h)} A_{j}
$$

$A_{j}$ è a função de absorção calculada para os quatro ân gulos correspondentes ao conjunto $j$. Eles podem ser diretamente os ângulos difratométricos (por exemplo, $\theta, \omega, x, \phi$ em um típico "Eulerian Cradle") ou qualquer conjunto equivalente referido a al gum outro sistema de coordenadas.

Em nosso caso particular é conveniente escolher como variáveis os dois pares de ângulos que definem as direções dos 
feixes incidente e difratado num sistema ortogonal fixo ao cris tal; desta maneira, ficará mais simples visualizar a relação en tre a função de absorçāo e a geometria do experimento.

Chamando de $\underset{\sim}{p}$ e $\underset{\sim}{s}$ estas direções, podemos escrever (II.1) na forma equivaîente à de Kopfmann e Huber (I.3)

$$
I^{O}(\underset{\sim}{h}, j)=I^{T}(\underset{\sim}{h}) T(\underset{\sim}{p}, \underset{\sim}{s})
$$

sendo $\mathrm{T}(\underset{\sim}{\mathrm{p}}, \underset{\sim}{\mathrm{s}})$ a transmissão do cristal para o par de direções $\underset{\sim}{\mathrm{p}}$ e s. dos.

Tanto $\mathrm{I}^{\mathrm{T}}(\underset{\sim}{\mathrm{h}})$ como $\mathrm{T}(\underset{\sim}{\mathrm{p}}, \underset{\sim}{\mathrm{s}})$ são, em princípio, desconheci

O problema fundamental que apresenta o sistema de equa ções (II.2) é o seu carāter de não-1inearidade. Kopfmann e Huber contornam esse inconveniente introduzindo a hipótese de que a transmissão pode ser fatorada em transmissões parciais (I.4) e reescrevendo as equações em termos de seus logaritmos. Dessa ma neira fica definido um sistema linear no logaritmo das transmis sões parciais, tomadas nos pontos de uma rede previamente deter minada (vide I.3).

Neste trabalho, no entanto, tentamos uma abordagem di ferente explicitada a seguir.

Definimos $I^{T}(\underset{\sim}{h})$ para cada vetor recíproco $\underset{\sim}{h}$ como a má xima intensidade obtida para esse vetor ou qualquer dos seus equivalentes de Laue. Dessa maneira a intensidade normalizada $J(\underset{\sim}{h}, j)$, definida por

$$
J(\underset{\sim}{h}, j)=I^{O}(\underset{\sim}{h}, j) / I^{T}(\underset{\sim}{h})
$$

fica limitada entre os valores 0 e 1 . Essa aproximação é usada no método de North, Phyllips e Mathews (I.2). Adotámo-1a por simplicidade, mas essa aproximação não é uma restrição essencial do método. Eventualmente, pode-se utilizar a aproximação de Kata- 
yama (I.8), que $\vec{e}$, inerentemente, mais exata.

Suporemos agora que a transmissão para o par de direções $\underset{\sim}{s}$ e p pode escrever-se como a média da transmissão na dire ção $\underset{\sim}{s}$ mais a transmissāo na direção $\underset{\sim}{\mathrm{p}}$

$$
\mathrm{T}(\underset{\sim}{\mathrm{p}}, \underset{\sim}{\mathrm{s}})=\frac{1}{2}\{\mathrm{~T}(\underset{\sim}{\mathrm{p}})+\mathrm{T}(\underset{\sim}{\mathrm{s}})\}
$$

Mais simplesmente, absorvendo o fator $1 / 2$ na defini ção de $T$, o sistema de equações (II.3) pode ser escrito

$$
J(\underset{\sim}{h}, j)=T(\underset{\sim}{p})+T(\underset{\sim}{s})
$$

Chamando de $\theta_{p}, \phi_{p}$ e $\theta_{s}, \phi_{s}$ os ângulos que definem as di reções de $\underline{s}$ e $p$ num sistema de coordenadas ortogonal fixo ao cris tal, e levando-se em conta que $T$ é uma função periódica desses ângulos, efetuamos o desenvolvimento

$$
T(\theta, \phi)=\sum_{n} \sum_{m}\left\{C_{n m} \cos (n \theta+m \phi)+S_{n m} \sin (n \theta+m \phi)\right\}
$$

com o que o sistema de equações (II.4) fica, finalmente

$$
\begin{aligned}
\sum_{n=0}^{N} \sum_{m=0}^{N}\left\{c _ { n m } \left[\cos \left(n \theta_{p_{j}}+m \phi_{p_{j}}\right)+\cos \left(n \theta_{s}+m \theta_{s_{j}}\right]+\right.\right. \\
+s_{n m}\left[\operatorname{sen}\left(n \theta_{p_{j}}+m \phi_{p_{j}}\right)+\sin \left(n \theta_{s_{j}}+m \theta_{s_{j}}\right)\right]
\end{aligned}
$$

Este é um sistema linear nas incógnitas $\mathrm{C}_{n m}$ e $\mathrm{S}_{n m}$ e 0 número delas é perfeitamente aceitāvel do ponto de vista prāti co (por exemplo, desenvolvendo-se ambas as variáveis até a ordem $\mathrm{N}=8$, o número total de termos é de 161).

A obtenção do sistema de equações (II.5) se baseia na 
aproximação (II.4), equivalente à (I.2), utilizada por North, Phyllips e Mathews, que contrasta marcadamente com a aproxima ção (I.4) de Kopfmann e Huber. Nos capítulos IV e V discutire mos as bases experimentais e teóricas que a sustentam.

Efetuando um nümero suficiente de medidas, o sistema (II.5) passa a ser super-determinado e pode ser resolvido pelo critério de mínimos quadrados. Isto será discutido no Capítulo I I .

A vantagem da formulação (II.5) è evidente. A resolução desse sistema dá diretamente a expressão analítica da fun ção de transmissão, em termos de uma série de Fourier. A soma dos valores dessa função, tomada nas duas direções $\mathbf{s} e \underset{\text { p }}{\mathrm{p}}$ dá a transmissão total para a reflexão por elas definida.

No restante deste capitulo analisaremos o arranjo experimental e a transformação desde a geometria Kappa até o sistema fixo do cristal, com o objetivo de poder construir explici tamente as equações do sistema (II.5).

\section{I. 2 Descrição do arranjo experimental}

O método foi implantado objetivando o uso do difratômetro CAD-4 da Enraf Nonius, que se utiliza atualmente no Laboratório de Cristalografia do Departamento de Física e Ciências dos Materiais de São Carlos.

0 desenho desse difratômetro difere marcadamente dos convencionais do tipo Euleriano. Consta de um goniômetro de três graus de liberdade (goniômetro Kappa), mais um quarto grau de li berdade para a posição do detector. Os sistemas Eureliano e Kappa estảo mostrados comparativamente na figura 2 .

o goniômetro Kappa é mostrado em detalhe na figura 3 , juntamente com o sistema de coordenadas apropriado ao propósito deste traba1ho.

Consiste basicamente de três partes associadas a três 


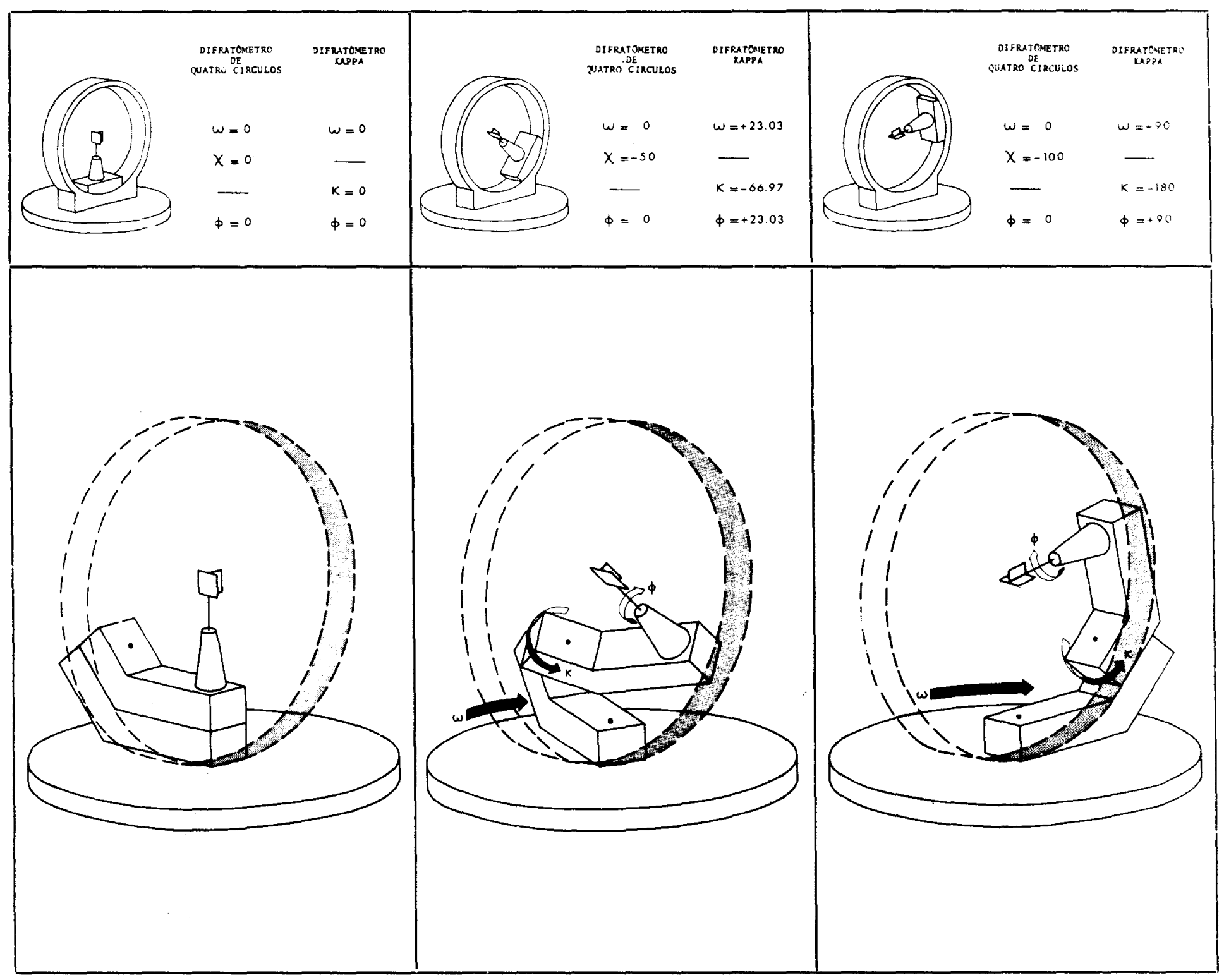

Figura 2

eixos de rotaçāo independentes.

A cabeça goniométrica está montada no eixo $\phi$, que, por sua vez, está apoiado no bloco Kappa $(k)$. Este bloco pode ser girado ao redor do eixo $k$, que é suportado pelo bloco $\omega$. Este, por sua vez, pode ser girado ao redor do eixo $\omega$, suportado pela base do difratómetro.

0 ângulo $\alpha$ entre os eixos k appa e ômega é nominalmente de $-50^{\circ}$. O mesmo vale para o ângulo entre $k$ e $\phi$. 


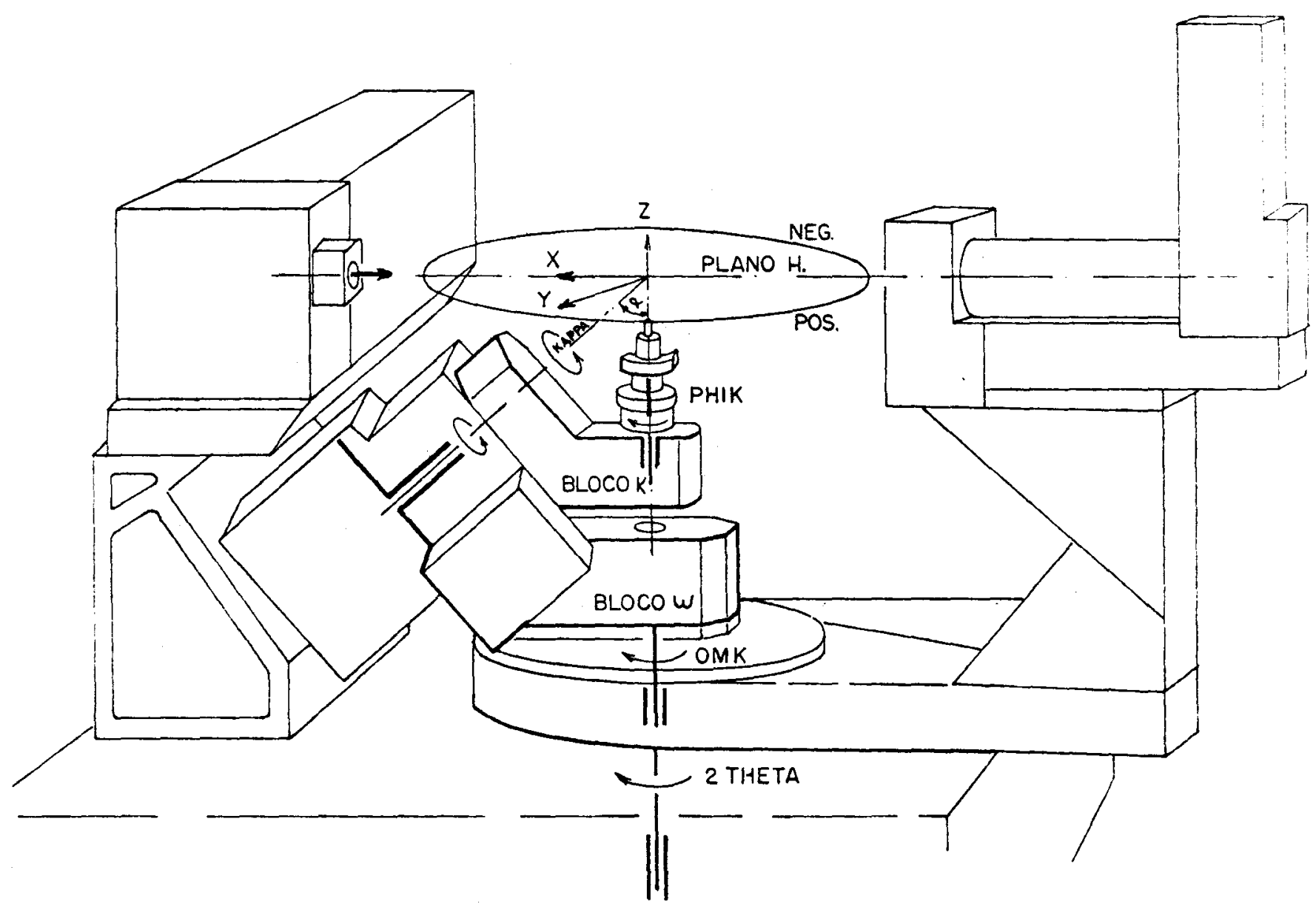

Figura 3

o plano através do centro do difratômetro e perpendicular a w é o"plano horizontal". A intensidade e a posição dos raios difratados são medidas nesse plano. O feixe primário também se encontra nesse plano, apontando para o centro do goniôme tro.

0 vetor dirigido do centro do goniômetro à fonte de raios-X é usado como o eixo X do sistema de coordenadas XYZ. O eixo $Z$ è tomado para cima, na direção de $\omega$ e o eixo Y completa um sistema ortogonal direito.

o detector está associado a um eixo $2 \theta$ independente, 
coincidente com o eixo $\omega$.

As posições zero dos ângulos kappa, ômega e 2-teta são definidas em termos da geometria do instrumento. O ângulo $k$, pa ra o qual os eixos $\omega$ e $\phi$ coincidem, è definido como $k=0 . \omega=0$ é definido como a posição na rotação do eixo ômega para a qual o eixo kappa fica no plano $X z$ e o bloco kappaé oposto à direção $+x$.

A posição $2 \theta=0$ é definida como a rotação teta na qual o detector coincide com a direção-X.

Finalmente, $\phi=0$ è arbitrariamente definido como 0 ponto na rotação $\phi$ em que a trava da cabeça goniométrica é paralela ao eixo $+Y$, quando $k$ e $\omega$ são simultaneamente zero.

Partindo de $k=0$ e $\omega=0$, os sentidos de rotação se defí nem da seguinte maneira: rotação positiva $2 \theta$, $\omega$ e $\phi$ levam o vetor $Y$ para o vetor $X$; rotação positiva ao redor de $k$ leva o vetor Y para uma posição abaixo do plano horizontal.

Esquematicamente o difratômetro opera da seguinte maneira: com o cristal geometricamente centrado na intersecção dos eixos do goniómetro, o primeiro passo é encontrar a orientação absoluta do sistema cristalino recíproco $a^{*} b^{*} c^{*} \operatorname{com}$ respeito ao sistema XYZ fixo à cabeça goniométrica. Para este fim é necessá rio que o difratômetro tenha centrado e armazenado as posições angulares de um certo número de reflexões. Isto pode ser conseguido de diversas maneiras, como por exemplo, medindo as coorde nadas de um certo número de reflexões obtidas fotograficamente numa câmara especialmente adaptada ao difratômetro, ou por simples varredura no espaço recíproco mediante rotações programa das dos ângulos difratométricos. Com essa informação calcula-se uma cela unitária tentativa. A anālise do tensor métrico asso ciado permite então obter a transformação à qualquer outra cela unitāria, eventualmente aquela que possua a simetria máxima do sistema $(11,12)$.

Todas estas etapas são efetuadas com a ajuda de um con 
junto de programas que permitem a rápida interação do operador com o sistema $(18)$.

Com o cristal já orientado, o posicionamento de uma reflexão consiste em efetuar as rotações necessārias para levar - vetor recíproco a bissetar no plano horizontal as direções dos feixes incidente e difratado. A descrição detalhada dos cálculos necessários numa montagem Eureliana tem sido extensamente desenvolvida $(7)$.

No caso da geometria Kappa efetuam-se cálculos intermediārios numa geometria Eureliana associada, e utiliza-se a seguir a transformação entre ambas dada pelo conjunto de rela ções (13)

$$
\begin{aligned}
& \operatorname{sen} \frac{x}{2}=\operatorname{sen} \frac{\pi}{3,6} \operatorname{sen} \frac{\kappa}{2} \\
& \omega_{k}=\omega_{e}-\delta \\
& \operatorname{tg} \delta=\cos \frac{\pi}{3,6} \operatorname{tg} \frac{\kappa}{2}
\end{aligned}
$$

onde $x$ e $\omega_{e}$ são ângulos Eurelianos.

A obtenção dos ângulos que definem os feixes incidente e difratado com respeito a um sistema fixo ao cristal não está prevista no "software" do difratômetro. Felizmente seu cálcu10 não requer a complicação adicional de passar por um sistema Eureliano e pode ser obtido por meio de poucas operações linea res sobre os ângulos da geometria Kappa como é mostrado a seguir.

II.3 Cálculo das direções dos feixes primärio e secundário com respeito a um sistema de coordenadas fixo ao cristal, na geometria Kappa

O difratômetro CAD-4 tem incluida no seu "software" a 
facilidade de efetuar automaticamente a medida de uma reflexão para intervalos do ângulo azimutal especificados pelo operador.

Em cada medida toda a informação relacionada com uma reflexão dada é armazenada num arquivo em disco ou fita magnétí ca. Essa informação inclui os quatro ângulos que definem a re flexão na geometria Kappa. O problema que se apresenta é calcular a partir deles as direções dos feixes incidente e difratado num sistema de coordenadas xyz fixo ao cristal.

Este sistema deve ser convenientemente ortogonal, razão pela qual o definiremos em termos do sistema cristalino recíproco $\underset{\sim}{a}{ }_{\sim}^{*}{ }^{*} c^{*}$, tal que

$$
\begin{aligned}
& x \text { estā na direção de }{\underset{\sim}{a}}^{*} \\
& \text { y está no plano } \underset{\sim}{a}{\underset{\sim}{b}}^{*} \\
& z \text { é perpendicular ao plano }{\underset{\sim}{a}}^{*} \stackrel{\sim}{*}^{*}, \text { e formando uma terna }
\end{aligned}
$$
direita.

Seja um vetor arbiträrio $\underset{\sim}{v}$, referido ao sistema $\underset{\sim}{a}{ }_{\sim}^{b^{*} c^{*}}$. Com respeito ao sistema ortogonal $x y z, \underset{\sim}{\mathrm{v}}$ toma a forma

$$
\underline{v}_{C}=B \underset{v}{v}
$$

sendo $B$ a matriz super-triangular de ortogonalização(14)

$$
B=\left[\begin{array}{ccc}
{\underset{\sim}{a}}^{*} & \underset{\sim}{b} \cos \gamma^{*} & \stackrel{\sim}{c}{ }^{*} \cos \beta^{*} \\
0 & \stackrel{\sim}{b}^{*} \operatorname{sen} \gamma^{*} & -\underset{\sim}{c} \operatorname{sen} \beta^{*} \cos \alpha \\
0 & 0 & 1 / \underset{\sim}{c}
\end{array}\right]
$$

onde os parâmetros sem asterisco se referem à cela direta. Analisaremos agora como se transforma $\underset{\sim}{v}$, a) para uma 
orientação arbitrária do cristal, com respeito à cabeça goniomé trica e b) para valores arbiträrios dos ângulos difratométri $\cos$.

a) Referido a um sistema ortogonal XYZ, fixo à cabeça goniométrica, e tal que quando todos os ângulos difratomé tricos são zero coincide com o sistema XYZ da figura 3, o vetor $\sim_{C}$ toma a forma

$$
\underset{\sim}{\mathrm{v}}=\underset{\sim \mathrm{C}}{\mathrm{UV}}=\mathrm{UB}_{\sim}^{\mathrm{v}}=\mathrm{R} \underset{\sim}{\mathrm{v}}
$$

onde R=UB é a chamada "matriz de orientação". Sua determinação é efetuada com a ajuda de algoritmos fornecidos pelo "software" do difratômetro (vide (II.2)).

b) 1. Transformação do vetor $\underset{\sim}{v}$ por uma rotação ao redor de $\phi$.

Com todos os outros ângulos difratométricos iguais a zero, esta operação é equivalente a girar $\underset{\sim}{\mathrm{v}}$ num ângulo $\phi$ ao redor do eixo $Z$. Resulta:

$$
\underset{\sim}{\mathrm{v}_{\mathrm{g}}^{\prime}}=\mathrm{Z}(-\phi) \stackrel{\mathrm{v}}{\sim \mathrm{g}}
$$

onde

$$
Z(\phi)=\left[\begin{array}{ccc}
\cos \phi & -\operatorname{sen} \phi & 0 \\
\operatorname{sen} \phi & \cos \phi & 0 \\
0 & 0 & 1
\end{array}\right]
$$


b) 2. Transformação de $\underset{\sim}{v}$ por uma rotação ao redor de $k$.

Consideremos primeiro uma rotação imaginäria ao redor do eixo $Y$, que leve o eixo $\phi$ a coincidir com o eixo $\mathrm{k}$.

A seguir realizamos uma rotação ao redor de $k$, agora coincidente com uma rotação ao redor de $\phi$ e restituimos final mente o eixo $k$ à sua posição original com uma "rotação" inversa à primeira. 0 resultado final é

$$
\underset{\sim}{v_{g}^{\prime \prime}}=Y(-\alpha) Z(-k) Y(\alpha) v_{g}^{\prime}
$$

onde

$Y(\alpha)=\left[\begin{array}{ccc}\cos \alpha & 0 & -\operatorname{sen} \alpha \\ 0 & 1 & 0 \\ \operatorname{sen} \alpha & 0 & \cos \alpha\end{array}\right]$

b) 3. Transformação de $\underset{\sim}{v_{g}^{\prime \prime}}$ por uma rotação ao redor de $\omega$.

Como o eixo $\omega$ coincide com $\circ$ eixo $Z$, esta transformação é dada diretamente pela matriz $z(-\omega)$.

Finalmente, ${\underset{\sim}{g}}_{g}$ se transforma diante de rotações dos ângulos $\phi, k$ e $\omega$ em $\underset{\sim}{v} \underset{ }{v}$ da forma

$$
{\underset{\sim}{v} \phi K \omega}=Z(-\omega) Y(-\alpha) Z(-\kappa) Y(\alpha) Z(-\phi){\underset{\sim g}{v}}_{g}
$$

Definindo o sistema de coordenadas esféricas em relação ao sistema $X Y Z$ mediante 


$$
\begin{aligned}
& X=R \cos \phi \operatorname{sen} \theta \\
& Y=R \operatorname{sen} \phi \operatorname{sen} \theta \\
& Z=R \cos \theta
\end{aligned}
$$

os ângulos $\theta$ e $\phi$, associados com um vetor de componentes ( $u, v$, w), são dados por

$$
\operatorname{tg} \phi=\frac{v}{u} ; \quad \operatorname{tg} \theta=\frac{\sqrt{u^{2}+v^{2}}}{w}
$$

Em particular, com respeito ao sistema XYZ e quando $w$, k e $\phi$ são zero, o versor $\underset{\sim}{p}$ tem componentes

$$
\underset{\sim}{\mathrm{p}}=\left[\begin{array}{l}
1 \\
0 \\
0
\end{array}\right]
$$

e o versor s é tal que

$$
Z(2 \theta) \underset{\sim}{\mathbf{s}}=\left[\begin{array}{c}
-1 \\
0 \\
0
\end{array}\right]
$$

ou seja

$$
\underset{\sim}{s}=2(-2 \theta)\left[\begin{array}{r}
-1 \\
0 \\
0
\end{array}\right]
$$

Com o uso das equações (II.9) e (II.10), $\theta_{p}, \phi_{p}$ e $\theta_{s}$ e $\phi_{S}$ podem ser calculados para qualquer valor dos ângulos difrato métricos. 


\section{CAPITULO II I}

ANALLISE NUMERICA DO PROBLEMA

\section{III.1 Solução do sistema de equações}

As equações (II.5) formam um sistema linear superde terminado cuja solução pode ser obtida pelo critério de mínimos quadrados.

Em Cristalografia há grande número de problemas cuja formulação matemática se expressa na forma (II.5). Por essa razão achamos conveniente desenvolver um programa do tipo "general purpose" para resolver um sistema com um número arbiträrio de $\underline{\mathrm{e}}$ quaçōes e de incógnitas $(M, N, M>N)$.

Com a configuração atual do computador PDP $11 / 45$, o nú mero máximo de incógnitas é de aproximadamente 100 , sendo que o número de equações é praticamente ilimitado.

Desenvolve-se, a seguir, uma formulação matricial com pacta do método de mínimos quadrados, que se adapta diretamente ao cálculo computacional.

Seja

$$
A \underset{\sim}{x}=\underset{\sim}{b}
$$

- sistema de equações lineares ("observational equations") onde A é uma matriz de $N \times M(M>N), \underset{\sim}{b}$ é um vetor de ordem $M$ e $\underset{\sim}{x}$ é o ve tor das incógnitas de ordem $N$. Se o sistema de equações surge de observações experimentais, existirão erros afetando os valores de $A$ ou de b ou de ambos e é muito pouco provável que o sis tema admita solução. Procura-se então uma solução que minimize de alguma maneira o modo em que as equações (III.I) não são satisfeitas. Suporemos que as equações são independentes e igualmente precisas. 


$$
\begin{aligned}
& \text { Define-se o vetor resíduo } \underset{\sim}{r} \\
& \underset{\sim}{r}=\underset{\sim}{b}-A \underset{\sim}{x}
\end{aligned}
$$

e constroe-se a soma do quadrado de erros, $\mathrm{R}$, da forma

$$
R=\underset{\sim}{r} \stackrel{T}{r}
$$

A solução de (III.1) que satisfaz o critério de minimos quadrados é a que minimiza a função $R$, chamada por essa razão de "função de minimização".

$$
\text { Desenvolvendo (III.3) }
$$

$$
\mathrm{R}=(\underset{\sim}{b}-\mathrm{Ax} \underset{\sim}{\mathrm{x}})^{\mathrm{T}}(\underset{\sim}{\mathrm{b}}-\underset{\sim}{\mathrm{Ax}})={\underset{\sim}{\mathrm{b}}}^{\mathrm{T}} \underset{\sim}{\mathrm{b}}-\underset{\sim}{\underset{\sim}{\mathrm{b}}}{ }^{\mathrm{A}} \underset{\sim}{\mathrm{x}}+\underset{\sim}{x^{\mathrm{T}}} \mathrm{A}^{\mathrm{T}} \mathrm{Ax} \underset{\sim}{\mathrm{x}}
$$

onde usamos o fato de que

$$
\underset{\sim}{\mathrm{b}}{ }^{\mathrm{A}} \underset{\sim}{\mathrm{x}}=(\underset{\sim}{\mathrm{x}})^{\mathrm{T}} \underset{\sim}{\mathrm{b}}
$$

Com as condições de extremo $\partial R / \partial \underset{\sim}{x}=0$, isto $\vec{e}$, a anulação das derivadas da função de minimização em relação a cada uma das incógnitas, obtém-se

$$
-2 \underset{\sim}{\mathrm{b}}{ }^{\mathrm{T}} \mathrm{A}+2 \underset{\sim}{\mathrm{x}}{ }^{\mathrm{T}} \mathrm{A}^{\mathrm{T}} \mathrm{A}=0
$$

ou seja

$$
\mathrm{A}^{\mathrm{T}} \underset{\sim}{\mathrm{x}}=\mathrm{A}^{\mathrm{T}} \underset{\sim}{\mathrm{b}}
$$

solução

As (III.4) são conhecidas como "equações normais". Sua

$$
\underset{\sim}{x}=\left(A^{T} A\right)^{-1} A^{T} \underset{\sim}{b}
$$


dá as $N$ componentes de $\underset{\sim}{x}$ que melhor satisfazem as (III.1) no sen tido de minimizar (III.3).

A matriz $\mathrm{A}^{\mathrm{T}} \mathrm{A}$ é, por construção, simétrica e definida

positiva e pode, portanto ser fatorada na forma $\mathrm{LL}^{\mathrm{T}}$, sendo $\mathrm{L} u \mathrm{ua}$ matriz infratriangular(15). Este processo é conhecido como decom posição de Choleski. Pode-se demonstrar que todos os números que nela aparecem estão limitados pelos elementos diagonais da ma triz original, razão pela qual os problemas de grandes multiplicadores que ocorrem na fatoração LU ( $L$ infratriangular, $U$ supertriangular) de uma matriz arbitrāria não aparecem aqui (16).

o algoritmo de Choleski é extremamente estável ${ }^{(1)}$, eis porque é preferível a outros métodos utilizados com matrizes ge rais não necessariamente definidas positivas.

o processo de resolução de (III.4) é o seguinte:

A matriz $C=A^{\mathrm{T}} \mathrm{A}$ é fatorada na forma

$C=L L^{T}$

com L infratriangular. Logo

$$
C^{-1}=\left(L L^{T}\right)^{-1}=\left(L^{T}\right)^{-1} L^{-1}=\left(L^{-1}\right)^{T} L^{-1}
$$

e o problema se reduz a inverter L.

O diagrama de fluxo para a decomposição de Choleski foi tomado de ${ }^{(14)}$. De sua análise pode-se observar que nenhum $c_{i j}$ (e lemento da matriz C) é necessário depois de formar o elemento $l_{i j}$ (elemento da matriz L). E possível, então, sobrescrever C progres sivamente com L, necessitando-se apenas $\mathrm{N}(\mathrm{N}+1) / 2$ posições de memó ria para A e L.

A matriz infratriangular $\mathrm{L}$ pode ser invertida elemento a elemento, usando-se a relação $L L^{-1}=I$ e calculando-se os elementos de I na ordem $(1,1),(1,2),(1,3), \ldots,(1, N),(2,2),(2,3), \ldots$, $(2, N), \ldots,(N, 1),(N, 2),(N, 3), \ldots,(N, N)$. Como $L^{-1}$ também é infratriangular, apenas um elemento desconhecido aparece em cada etapa. $\left(\mathrm{L}^{\mathrm{T}}\right)^{-1} \overline{\mathrm{e}}$ 
simplesmente $\left(\mathrm{L}^{-1}\right)^{\mathrm{T}}$. O diagrama de fluxo desenvolvido para a inversão de L é mostrado no Apêndice.

Novamente pode-se sobrescrever $\mathrm{L}_{\text {por }} \mathrm{L}^{-1}$ e $\mathrm{L}^{-1}$ por $\mathrm{C}^{-1}$ (apenas os elementos diferentes), de maneira que não é necessária memória adicional.

III.2 Sistema de programas desenvolvido

o sistema de cálculos do método está dividido em qua tro programas principais, que podem ser executados em sequéncia ou independentemente.

\section{Programa ABSOR}

E uma modificação do programa DATARED do sistema SDP ${ }^{(18)}$.

Usando como entrada os dados diretamente gerados pelo difratómetro, o programa ABSOR calcula as amplitudes de difração, $\operatorname{sen} \theta$, fator de Lorentz, etc...Simultaneamente aplica as transfor mações discutidas na secção II.3 para obter os ângulos corres pondentes às direções $\underset{\sim}{\mathrm{p}} \mathrm{e}$.

Gera dois arquivos em disco:

DIFRAC.DAT, no qual toda a informação relevante (índices de Miller, intensidade, ângulos, etc...) é armazenada para cada reflexão.

INTFAC.DAT. Arquivo intermediário usado por todos os programas, onde è guardada informação de tipo geral, tal como nú mero de equações, número de incógnitas, nümero de diferentes $\underset{\sim}{\mathrm{h}}$, etc... e onde na etapa final serão armazenados os coeficientes de ( I I. 5 ).

\section{Programa INTFAC}

Gera a matriz das "observational equations", usando o arquivo DIFRAC.DAT e a ordem da série $N$, que é lida pela termi - 
nal.

A expansão pode ser efetuada em série de senos, de co senos, ou de ambos. O máximo valor de $\mathrm{N}$ compatível com a configuração atual do computador é 8 para série de senos ou série de cosenos e 5 para série de senos e cosenos. A e $\underset{\sim}{b}$ são armazena dos num único arquivo OBSERV.DAT.

\section{Programa LSTSQ}

Forma as equaçōes normais a partir das observações, as inverte e calcula as incógnitas.

Devido à configuração do computador, a formação de $C=$ $=\mathrm{A}^{\mathrm{T}} \mathrm{A}$ não pode ser realizada na memória. A formação do elemento $C_{i j}$ de $C$ é o produto escalar da coluna i pela coluna $j$ da ma triz A. Como num arquivo de "random access" a leitura se efetua por linhas e não por colunas, fica mais económico, do ponto de vista de tempo de máquina, obter primeiramente $A^{T}$ e usar esta para calcular C. Para otimizar esta operação o programa incor pora uma subrotina que aproveita a memória reservada (alocated) para C como "buffer" temporärio para efetuar a transposição na memória por etapas. Com isso foi reduzido aproximadamente à metade o tempo de formação de $C$, apesar do mesmo continuar domi nando o tempo total do processo.

No caso teste descrito no próximo capítulo, para um sistema de 183 equações com 80 incógnitas, a formação das equações normais demorou aproximadamente 7 minutos enquanto que o restante do processo demorou apenas 27 segundos.

\section{Programa SERIE}

Soma a sërie de Fourier (II.5) para obter a transmissão (fator de correção) para cada reflexão. 


\section{CAPITULO IV \\ APLICAÇAO A UM CASO TESTE}

A fim de testar seu comportamento, o método foi aplicado a um cristal de $\mathrm{KPF}_{6}$, pertencente ao sistema cúbico, obtido como um fragmento de morfologia irregular da ruptura de um monocristal excessivamente grande para estudos difratométricos.

Suas dimensões aproximadas são de $0.2 \times 0.3 \times 0.5 \mathrm{~mm}$ e seu coeficiente de absorção linear $\mu=15.0 \mathrm{~cm}^{-1}$ para a radiação $\kappa_{\alpha}$ de molibdênio utilizada.

Devido às suas caracteristicas morfológicas, este cris tal apresenta uma absorção altamente anisotrópica e relativamen te elevada. A essas condições, ideais para sua utilização como cristal de teste, soma-se a grande estabilidade do composto, que permite trabalhar durante períodos praticamente ilimitados sem as complicações adicionais de danos causados por radiação(radia tion damage).

Onze reflexões com vetores recíprocos em direções ar bitrárias foram escolhidas com a única precaução de que suas in tensidades não fossem demasiado fortes para sofrer o fenômeno da extinção, nem demasiado fracas para aumentar desnecessariamente o tempo de medição.

0 difratômetro foi programado para medir as intensidades de todas as reflexões em etapas de $10^{\circ}$ do ângulo azimutal. Como nem todas as posições correspondentes aos distintos valores de $\psi$ são compatíveis com a geometria do difratômetro devido a pro blemas de colisão das suas partes móveis (com exceção das direções aproximadamente paralelas à do eixo da cabeça goniométrica), apenas 183 medidas independentes foram realizadas.

Essas reflexões foram processadas pelo programa ABSOR (veja III.2), cuja saída é apresentada na tabela I. 
TABELI 1

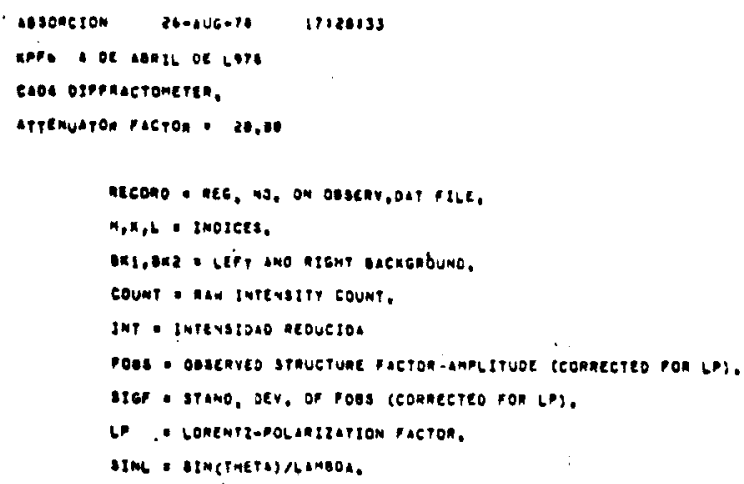


TABELA 1 (cont.)

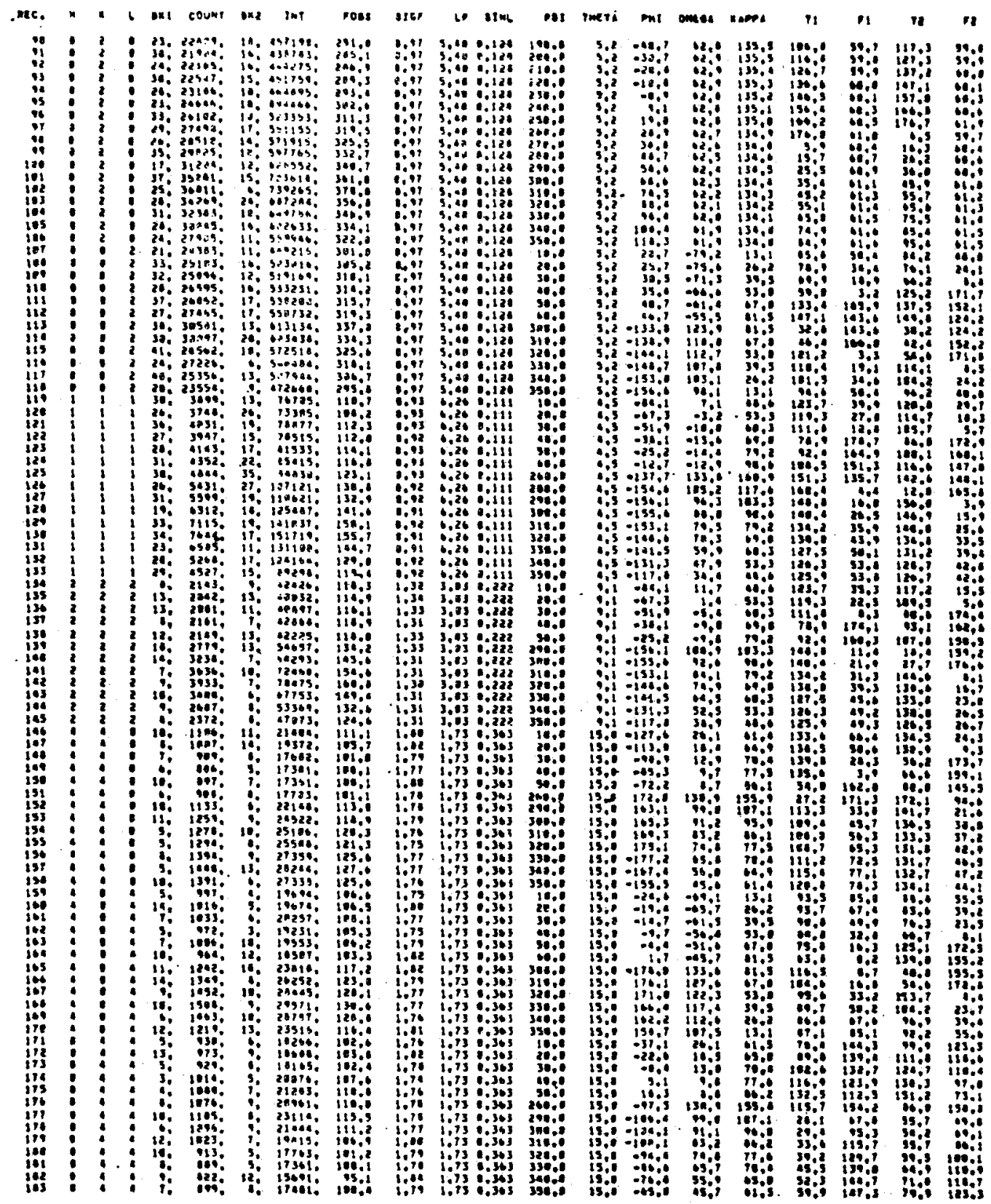

\footnotetext{
sumenen,

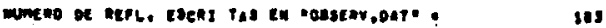

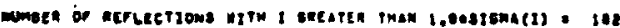

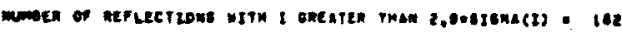

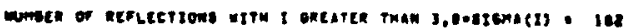

wimen of stamoano arfegetions. -

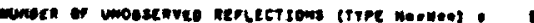

muncer oe reusetomes : ICS

mucte ot rectones neesproces , "1
} 
Para formar as "observational equations" a partir dos dados difratométricos, é necessärio primeiro definir a ordem má xima de termos $\mathrm{N}$ a serem incluidos na série. Isso depende pre ponderantemente da "redundância" do sistema, definida como o quo ciente entre o número de equações e o número de incógnitas.

Quando se mantém alta a redundância, todos os coefi cientes da série resultam menores do que a unidade e a descri ção de uma curva azimutal não incluida no sistema (II.5) é ge ralmente satisfatória dentro da precisão intrinsecamente limita da pelo termo de frequência mais alta do desenvolvimento.

Quando a redundância é menor do que um certo valor (a proximadamente 2 no caso teste), verifica-se que värios dos coe ficientes da série podem tomar valores às vezes bem maiores do que a unidade. Neste caso as curvas azimutais incluidas no sis tema de equação podem ainda ser satisfatoriamente aproximadas pela série, porém isso não ocorre em geral com outras curvas azimutais não incluidas no sistema (II.5).

Isso significa que neste caso o sistema de minimos qua drados continua ajustando a sèrie aos dados experimentais, mas esta perde o sentido físico de função de transmissão.

Se a (II.5) é desenvolvida apenas em série de senos (todos os $\mathrm{C}_{n \mathrm{~m}}=0$ ) ou apenas em série de cosenos (todos os $\mathrm{S}_{n m}=0$ ), o número de incógnitas do sistema è reduzido à metade.

Efetuando ambos os desenvolvimentos até $\mathrm{N}=8$, verifi cou-se que a série de senos e a série de cosenos resultantes são praticamente idênticas o que indica que as condiçōes de paridade impostas à função não afetam sensivelmente seu comportamento. Este resultado é previsível porque os extremos do intervalo dos ângulos $\theta$ e $\phi$, onde os efeitos de paridade poderiam ser mais importantes, não são praticamente atingidos (veja tabela I).

No caso teste estudado a ordem $\mathrm{N}=8$ è a máxima na qual a série de senos ou de cosenos pode ser seguramente expandida $e$ corresponde a uma redundância de aproximadamente 2,3 . Para $N=9$ a 
redundância diminui para 1,8 e alguns coeficientes da expansão (II.5) começam a resultar maiores do que a unidade.

$\mathrm{Na}$ figura 4 são apresentadas comparativamente as curvas experimentais e calculadas de todas as reflexões da tabela I, com $N=8$ e a série desenvolvida unicamente em termos de senos. os valores dos coeficientes $S_{n m}$ são apresentados na tabela II.

Um dos dados experimentais da reflexão 600, erronea mente medido como zero por uma falha circunstancial do fornecimento de energia elétrica, foi propositalmente incluido para ob servar o "smoothing" da função calculada.

Para observar a reprodução analítica de curvas azimutais arbitrárias, toda a informação correspondente a uma mesma reflexão hke da tabela I foi tirada do sistema (II.5) e os coe ficientes $S_{n m}$ foram calculados. Com estes coeficientes calculou se então a correspondente curva azimutal. Os resultados, obti dos para quatro reflexões diferentes, apresentam-se na figura 5 . 

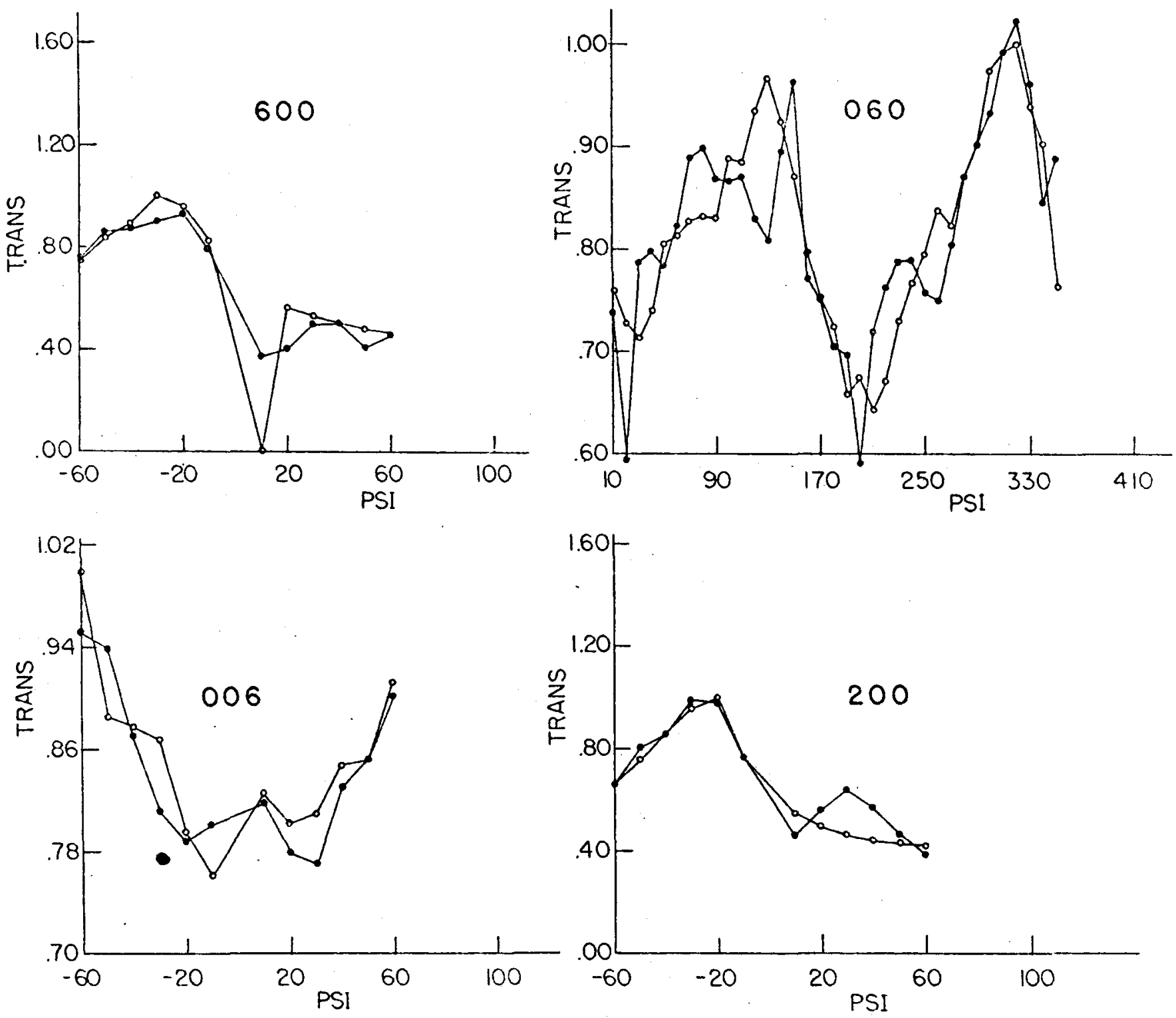

FIG. 4 

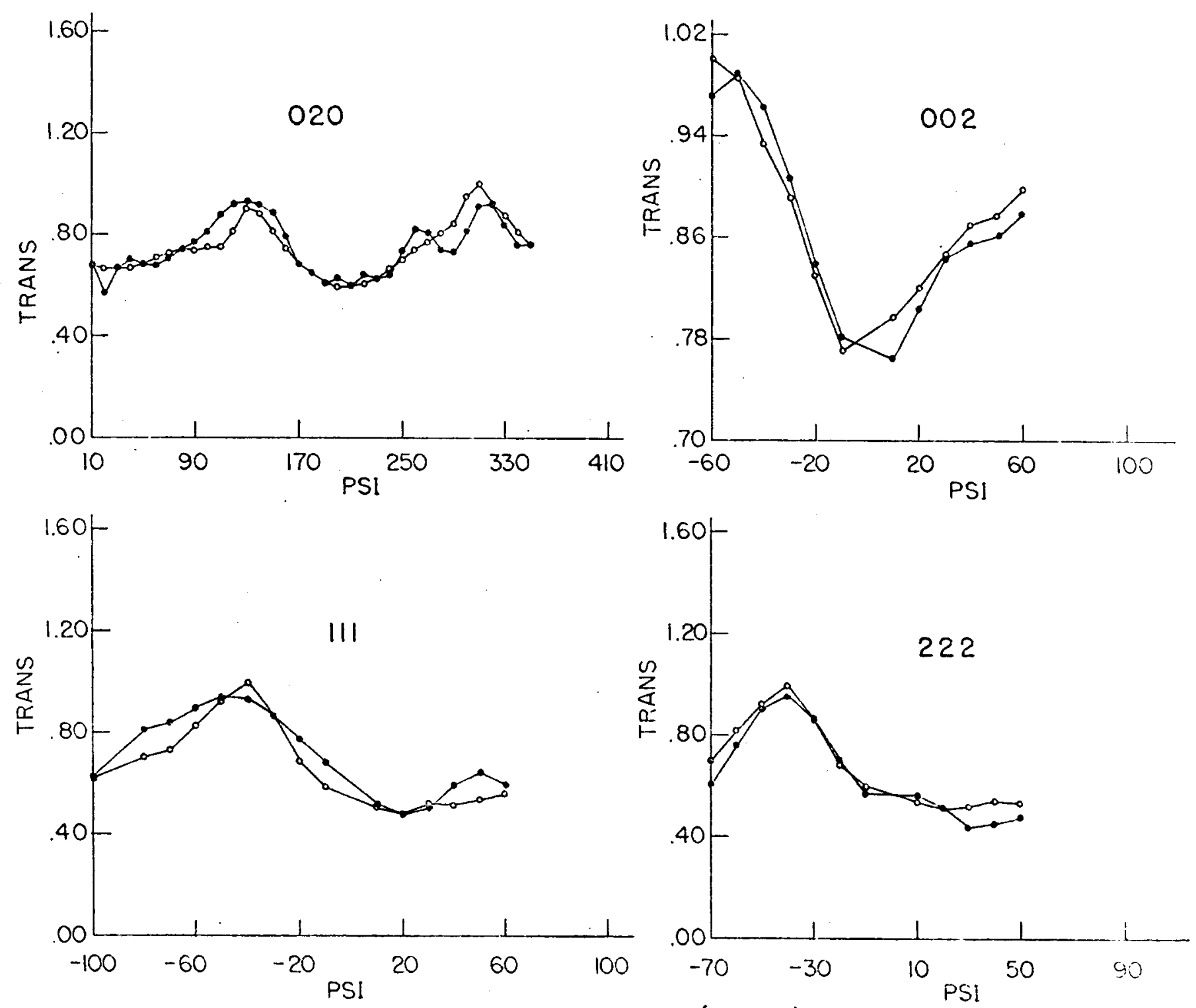

FIG 4 (CONT.) 
$-33-$
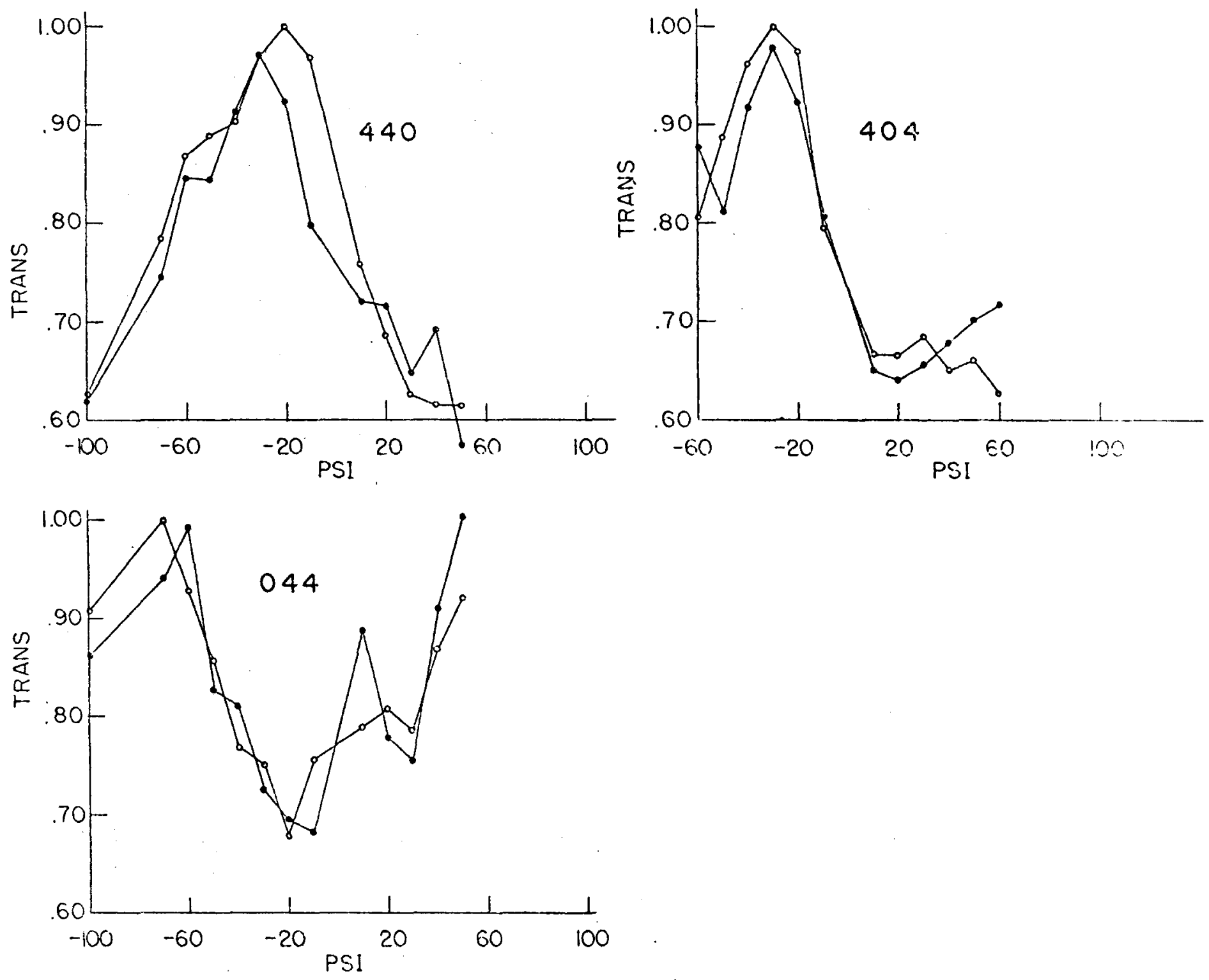

FIG. 4 (CONT.) 

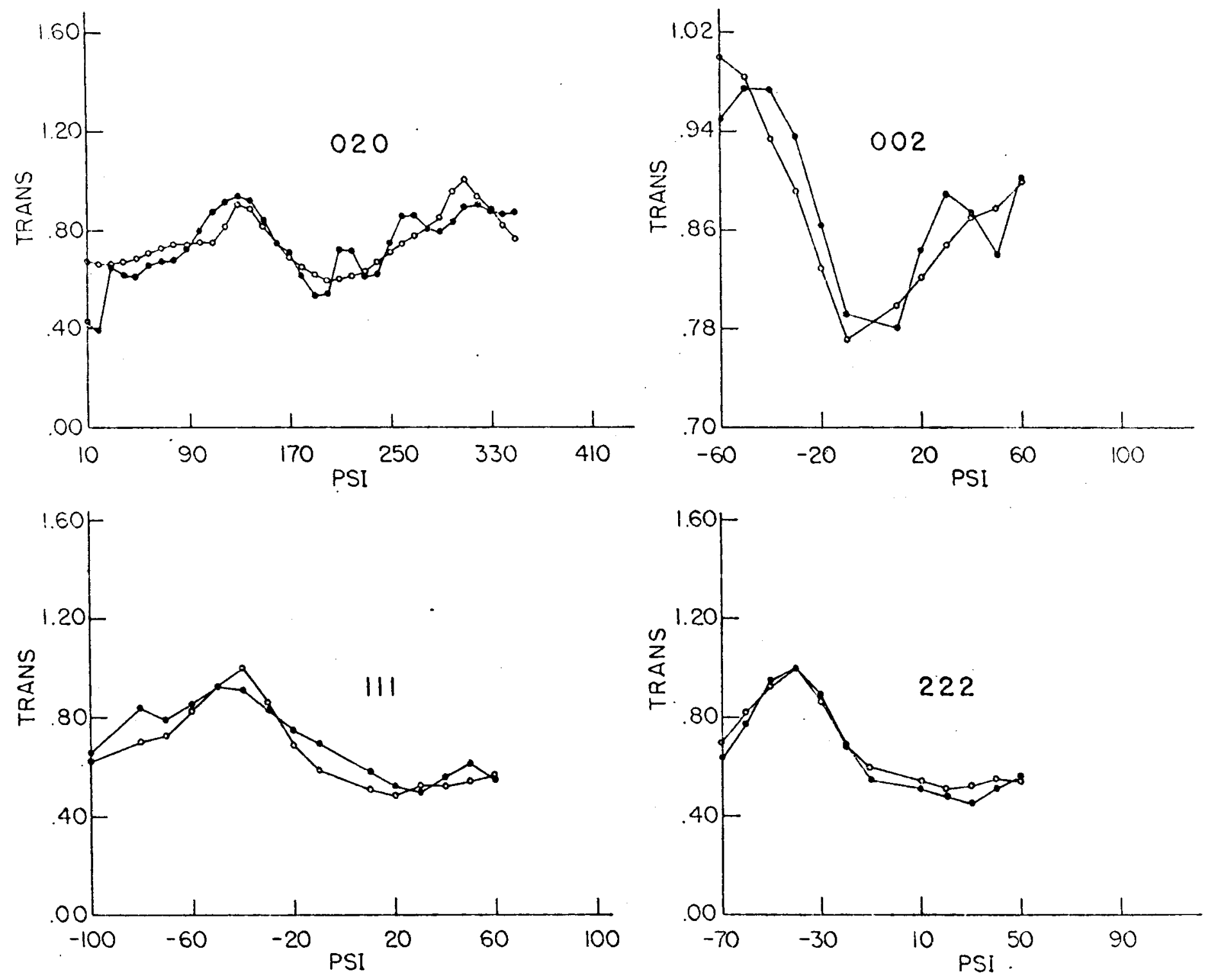

FIG. 5 
CAPITULO $\mathrm{V}$

DISCUSSAOO E SUGESTÃO PARA UM MELHORAMENTO

EVENTUAL NA PRECISAOO DO METODO

A aproximação fundamental em que o método está baseado consiste em decompor a função de transmissão na soma de dois termos, dependentes da direção do feixe incidente e do feixe di fratado respectivamente. Na verdade, pode-se mostrar que a fato ração desses termos é uma aproximação mais precisa do que a sua soma.

$$
\begin{aligned}
& \text { O argumento é o seguinte: } \\
& \mathrm{T}(\underset{\sim}{\mathrm{p}}, \underset{\sim}{\mathrm{s}}) \text { pode ser calculado mediante } \\
& \mathrm{T}(\underset{\sim}{\mathrm{p}}, \underset{\sim}{\mathrm{s}})=\frac{1}{\mathrm{~V}} \sum_{i} \exp \left[-\mu\left\{\mathrm{a}_{\mathrm{p}}\left(\mathrm{v}_{\mathrm{i}}\right)+\mathrm{a}_{\mathrm{s}}\left(\mathrm{v}_{\mathrm{i}}\right)\right\}\right] \Delta \mathrm{V}_{\mathrm{i}}
\end{aligned}
$$

onde $a_{p}\left(V_{i}\right)$ é a distância percorrida pelo feixe primário da superfície do cristal até o elemento de volume $v_{i} ; a_{s}\left(v_{i}\right)$ é a dis tância percorrida pelo feixe difratado, do elemento de volume $v_{i}$ à superfície do cristal e $\mu$ é o coeficiente de absorção line ar do cristal. Definimos as transmissões parciais

$$
\begin{aligned}
& T^{\prime}(\underset{\sim}{p})=\frac{1}{V} \sum_{i} \exp \left[\begin{array}{ll}
-\mu & \left.a_{p}\left(v_{i}\right)\right] \Delta v_{i}
\end{array}\right. \\
& T^{\prime}(\underset{\sim}{s})=\frac{1}{V} \sum_{i} \exp \left[\begin{array}{ll}
-\mu & \left.a_{s}\left(v_{i}\right)\right] \Delta v_{i}
\end{array}\right. \\
& \text { Em forma mais compacta, chamando } \\
& \exp \left[-\mu a_{p}\left(v_{i}\right)\right]=b_{i}^{p}
\end{aligned}
$$




$$
\exp \left[-\mu a_{s}\left(v_{i}\right)\right]=b_{i}^{s}
$$

teremos

$$
\begin{aligned}
T^{\prime}(\underset{\sim}{p}) T^{\prime}(s) & =\frac{1}{V^{2}} \sum_{i} b_{i} b_{i}^{s} \Delta v_{i}^{2}+ \\
& +\frac{1}{v^{2}} \sum_{i \neq j}^{\sum} b_{i} b_{j}^{s} \Delta v_{i} \Delta v_{j}
\end{aligned}
$$

Multiplicando-se ambos os membros de (V.2) por

$$
1=\frac{1}{V} \sum_{i} \Delta v_{i}
$$

obtemos

$$
T(\underset{\sim}{p}, \underset{\sim}{s})=\frac{1}{v^{2}} \sum_{i} b_{i}^{p} b_{i}^{s} \Delta v \underset{i}{2}+\frac{1}{v^{2}} \sum_{i \neq j}^{\sum_{i}} b_{i}^{p} b_{i}^{s} \Delta v v_{i} \Delta v j(V .3)
$$

A diferença entre (V.2) e (V.3) é a substituição de $b_{i}^{s}$ na primeira por $b_{j}^{s}$ na segunda.

$$
\text { (V.2) e (V.3) serão iguais se }
$$

$$
\underset{j \neq i}{\sum} b_{j}^{s} \Delta v_{i}=b_{i}^{s} \underset{j \neq i}{j} \Delta v_{j}
$$

Para os valores extremos de $b_{i}^{s}$ pode-se esperar uma equivalência aproximada entre (V.2) e (V.3), devido à soma sobre o indice $i$. Isto é, quanto menor o cristal e menor o coeficiente de absorção, melhor a exatidão da aproximação.

Cālculos de teste realizados por Kopfmann e Huber mos 
traram que a aproximação (I.4) é efetivamente boa até valores de $\mu$ de aproximadamente $40 \mathrm{~cm}^{-1}$.

No método de North, Phyllips e Mathews a aproximação (I.2) é menos restritiva que a (II.4) porque a média da trans missão em duas direções é tomada em casos isolados e não imposta como uma característica geral da função.

Apesar disso, a concordância entre dados experimentais e calculados, mostrada nas figuras 4 e 5 , sugere que (II.4) não è, de modo algum, uma má aproximação.

A razão desse fato pode ser depreendida da anālise se guinte :

Partindo de

$$
T(\underset{\sim}{p}, \underset{s}{s})=T^{\prime}(\underline{p}) \cdot T^{\prime}(\underset{\sim}{s})
$$

e propondo para $\mathrm{T}$ o desenvolvimento

$$
T(\underset{\sim}{p})=\sum_{n} \sum_{m} C_{n m} \cos \left(n \theta_{p}+m \phi_{p}\right)
$$

obtēm-se

$$
\begin{aligned}
& \mathrm{T}(\underset{\sim}{\mathrm{p}}, \underset{\sim}{\mathrm{s}})=\mathrm{C}_{00} \underset{\mathrm{n}=0}{\sum_{\mathrm{m}=0}^{N}} \sum_{\mathrm{nm}}^{\mathrm{N}}\left[\cos \left(\mathrm{n} \theta_{\mathrm{p}}+\mathrm{m} \phi_{\mathrm{p}}\right)+\right. \\
& n \cap m \neq 0 \\
& \left.+\cos \left(n \theta_{s}+m \phi_{s}\right)\right]+\sum_{n=0}^{N} \underset{m=0}{N} \sum_{n^{\prime}=0}^{N} m_{m^{\prime}=0}^{N} C_{n m^{\prime} n^{\prime} m^{\prime}}^{N}[\cos \\
& \mathrm{n} \cap \mathrm{m} \neq 0, \quad \mathrm{n}^{\prime} \cap \mathrm{m}^{\prime} \neq 0 \\
& \left.\left(n \theta_{p}+m_{p}\right){ }^{*} \cos \left(n^{\prime} \theta_{s}+m^{\prime} \phi_{s}\right)\right]
\end{aligned}
$$

onde a primeira soma dupla é obtida multiplicando-se o termo in dependente de $\mathrm{T}(\underset{\sim}{\mathrm{p}})$ por $\mathrm{T}(\underset{\sim}{\mathrm{s}})$ e reciprocamente. 
Quando os coeficientes de (V.4) são todos menores do que a unidade (veja Capitulo IV), a segunda soma dupla de (V.5) dominará evidentemente a soma total, tanto mais quanto menores forem os coeficientes. Mas essa soma dupla é precisamente a que se obtēm como expressão de $T$ quando se efetua a aproximação (II. 2). Isso significa que a escolha da forma funcional (V.4) para a função de transmissão conduz ao que poderíamos chamar de uma aproximação "hỉbrida" entre as alternativas de soma e fatoração, com a característica de ficar mais perto da aproximaçāo produto quanto menores forem os coeficientes de (V.4).

Da discussão precedente é evidente que a precisão do método poderia ser melhorada se se encontrasse uma forma sistemática de resolver o sistema de equações não lineares (V.5) obtido da aproximação de Kopfmann e Huber (I.4).

Nesse sentido tentou-se a seguinte alternativa: A fun ção (V.5) foi desenvolvida em série de Taylor até a primeira or dem e o sistema linear assim obtido foi resolvido para as incóg nitas $\Delta C_{n m}$. A expansão foi efetuada ao redor dos valores de $C_{n m}$ obtidos pela aproximação soma. O sistema converge em poucos ciclos mas, infelizmente, nas tentativas preliminares a convergência foi sempre para o minimo não físico (não global(16)).

o problema é obviamente, encontrar um conjunto de valores $\mathrm{C}_{\mathrm{nm}}$ suficientemente próximos do extremo global como para assegurar a convergência correta do sistema.

Existem métodos conhecidos para essa finalidade (16). Eventualmente pode ser encontrado um conjunto inicial dos $\mathrm{C}_{\mathrm{nm}}$ por simples tentativa e erro partindo-se de uma expansão em poucos termos de (V.5) e incrementando a série termo a termo. Em cada etapa todos os coeficientes deveriam ser refinados com a precaução de que as correções $\Delta C_{n m}$ aplicadas não produzam a mudança até outro mínimo vizinho. A eficácia deste procedimento ainda não foi verificada e pode ser objeto de posterior investi gação. 
As figuras 4 e 5 mostram que a descrição analítica da transmissão do cristal é globalmente satisfatória. Melhorar ain da mais a precisão do método pode requerer um aumento despropor cional no esforço de programação e no tempo de computação.

Ainda que o uso de um método mais preciso e sofistica do possa, em alguma análise particular, ser de importância fundamental, convém antes de começar a tarefa ter presentes os seguintes comentários extraídos do clássico livro de Buerger (Crystal Structure Analysis(19)).

"The correction for absorption is an exasperating one... It is such a large one that is better to apply an a proximate correction than none at all. For example if a needleshape crystal is used it is better to correct reflections for all levels by treating the absorption as if it were from a cy lindrical specimen whose diameter is the midle cross section of the needle".

o método proposto é, sem dúvida, muito mais preciso que a correção sugerida por Buerger, e é natural esperar-se que sua aplicação seja ūtil numa grande variedade de problemas que se apresentam em cristalografia molecular. 


\section{APENDICE}

\section{Algoritmo para Inverter uma matriz Infra- triangular}

Seja $A$ a matriz dada. A matriz inversa $B$ é tal que $A B=$ $=I$, ou explicitamente

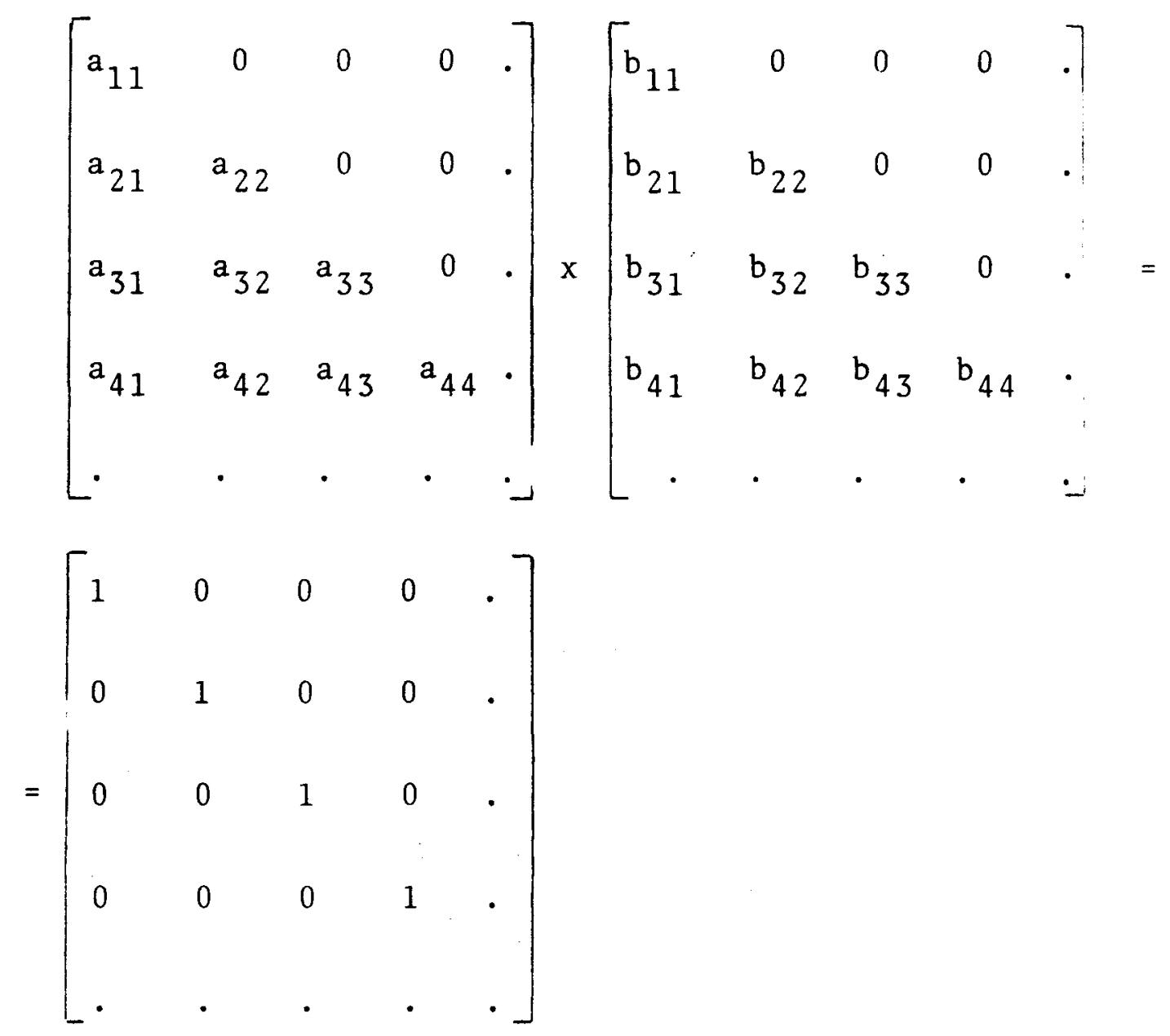

Segue-se que 
$b_{i i}=\frac{1}{a_{i i}}$

$b_{21}=-\frac{a_{21} b_{11}}{a_{22}}$

$b_{31}=-\frac{a_{31} b_{11}+a_{32} b_{21}}{a_{33}} ; b_{32}=-\frac{a_{32} b_{22}}{a_{33}}$

$b_{41}=-\frac{a_{41} b_{11}+a_{42} b_{21}+a_{43} b_{31}}{a_{44}} ; \quad b_{42}=-$

$-\frac{a_{42} b_{22}+a_{43} b_{32}}{a_{44}}$

Por indução obtém-se

$b_{i j}=-\frac{1}{a_{i i}} \sum_{k=j}^{i-1} a_{i k} b_{j k}, \quad i=j$

o algoritmo para calcular (A.1) e (A.2) é :

1 Faça $i=1$

2 Faça $b_{11}=1 / a_{11}$

3 Và para 11

4 Faça $j=1$

5 Faça $k=j, m=0$

$6 \quad m=n+a_{i k}, b_{k j}$

7 Incremente $k$, vá para 6 , até $k=i$ 
$8 \quad$ Faça $b_{i j}=-m / a_{i j}$

9 Incremente $j$, và para 5 até $j=1$

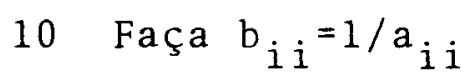

11 Incremente $i$, và para 4 até $i=n+1$

12 Fim

$n$ é a ordem da matriz. Os elementos $a_{i j} e b_{i j}$ são distinguidos neste algoritmo para estabelecer as fórmulas (A.1) e (A.2). Po de-se ver entretanto que nenhum $a_{i j}$ é requerido depois de que o correspondente $b_{i j}$ é armazenado. $a_{i j}$ e $b_{i j}$ podem portantoser colocados na mesma posição de memória. 
(1) International Tables for X-Ray Crystallography, vol.II. Bimmingham: Kynoch Press (1959).

(2) The Binding of Cupric Ions to Crystalline Sperm Whale Myoglobin. E.E.Castellano and Y.P.Mascarenhas. Resumos da 7 a.Reunião da Sociedade Brasileira de Cristalografia . DFCM de São Carlos (novembro de 1977).

(3) Meulenaer,J. de and Tompa,H. Acta Cryst.19,1044 (1965).

(4) Busing,W.R. and Levi,H.A. Acta Cryst.10,180 (1957).

(5) North,A.C.T., Phyllips,D.C. and Mathews,F.S. Acta Cryst. A24, 351 (1968).

(6) Furnas, T.C. Single Crystal Orienter Instruction Manual. Milwaukee: General Electric Company (1957).

(7) Busing,W.R. and Levi,H.A. Acta Cryst.22, 457 (1967).

(8) Kopfmann, G. and Huber, R. Acta Cryst.A24, 348 (1968).

(9) Huber, R. and Kopfmann, G. Acta Cryst.A25, 143 (1969).

(10) Katayama,C., Sakabe,N. and Sakabe,K. Acta Cryst.A28, 293, (1972).

(11) Azaroff,L.V. and Buerger,M.J. The Powder Method in X-Ray Crystallography. McGraw-Hill Book Company Inc. (1958).

(12) Roof,R.B. A Theoretical Extension of the Reduced Cell Concept in Crystallography. Report of the Los Alamos Scientific Laboratory, USA. Atomic Energy Commission (1969). 
(13) CAD-4 Operation Manual. Enraf Nonius, Delft, Holland, (August 1977).

(14) Computing Methods in Crystallography. Edited by J.S.Rollett. Oxford: Pergamon Press (1965).

(15) Bishop,R.E.D., Gladwel1,G.M.L. and Michelson,S. The Matrix Analysis of Vibration. Cambridge University Press, London and New York, p.265 (1965).

(16) Kowalik,J. and Osborne,M.R. Methods for Unconstrained Optimization Problems. American Elsevier Publishing Company Inc. New York (1968).

(17) Wilkinson,J.H. Error Analysis of Direct Methods of Matrix Inversion. J.Assoc.Comput.Mech. $\underline{8}, 281$ (1961).

(18) Enraf Nonius Structure Determination Package. Delft, Holland (1975).

(19) Buerger,M.J. Crystal-Structure Analysis. John wiley $\&$ Sons.Inc., New York, London, Sydney (1960). 